\title{
Lung imaging during acute chest syndrome in sickle cell disease: computed tomography patterns and diagnostic accuracy of bedside chest radiograph
}

\author{
Armand Mekontso Dessap, ${ }^{1,2,3}$ Jean-François Deux, ${ }^{2,4}$ Anoosha Habibi, ${ }^{5}$ Nour Abidi, ${ }^{1}$ \\ Bertrand Godeau, ${ }^{2,6}$ Serge Adnot, ${ }^{2,7}$ Christian Brun-Buisson, ${ }^{1,2}$ Alain Rahmouni, ${ }^{2,4}$ \\ Frederic Galacteros, ${ }^{2,5}$ Bernard Maitre ${ }^{2,8}$
}

- Additional material is published online only. To view please visit the journal online (http://dx.doi.org/10.1136/ thoraxjn-2013-203775)

For numbered affiliations see end of article.

\section{Correspondence to} Professor Armand Mekontso Dessap, Service de Réanimation Médicale, $\mathrm{CHU}$ Henri Mondor, 51 Av Mal de Lattre de Tassigny, Créteil, Cedex 94 010, France; armand.dessap@hmn.aphp.fr

Received 13 May 2013 Revised 1 July 2013 Accepted 5 July 2013 Published Online First 7 August 2013
To cite: Mekontso Dessap A, Deux J-F, Habibi A, et al. Thorax 2014;69:144-151.

\section{ABSTRACT}

Introduction The lung computed tomography (CT) features of acute chest syndrome (ACS) in sickle cell disease patients is not well described, and the diagnostic performance of bedside chest radiograph (CR) has not been tested. Our objectives were to describe $\mathrm{CT}$ features of ACS and evaluate the reproducibility and diagnostic performance of bedside CR.

Methods We screened 127 consecutive patients during 166 ACS episodes and 145 CT scans (in 118 consecutive patients) were included in the study. Results Among the 145 CT scans, 139 (96\%) exhibited a new pulmonary opacity and $84(58 \%)$ exhibited at least one complete lung segment consolidation. Consolidations were predominant as compared with ground-glass opacities and atelectasis. Lung parenchyma was increasingly consolidated from apex to base; the right and left inferior lobes were almost always involved in patients with a new complete lung segment consolidation on CT scan (98\% and 95\% of cases, respectively). Patients with a new complete lung segment consolidation on CT scan had a more severe presentation and course as compared with others. The sensitivity of bedside CR for the diagnosis of ACS using $\mathrm{CT}$ as a reference was good (>85\%), whereas the specificity was weak $(<60 \%)$.

Conclusions ACS more frequently presented on $\mathrm{CT}$ as a consolidation pattern, predominating in lung bases. The reproducibility and diagnostic capacity of bedside $C R$ were far from perfect. These findings may help improve the bedside imaging diagnosis of ACS.

\section{INTRODUCTION}

The term 'acute chest syndrome' (ACS) was first proposed in patients with sickle cell disease (SCD) by Charache $e t \mathrm{al}^{1}$ in 1979 as a description for 'the combination of chest pain, fever, increased leukocytosis, and appearance of a new shadow on chest radiograph (CR)'. Since then, many studies have focussed on this common complication of SCD that contributes significantly to mortality in adults, ${ }^{2}$ but the diagnostic criteria used varied from one report to another. The main difference between these criteria concerns the lung imaging definition which is more or less restrictive, including: 'a new pulmonary opacity', 'an acute pulmonary disease involving at least one complete lung segment', ${ }^{4}$ or 'a new pulmonary opacity involving at least one

\section{Key messages}

What is the key question?

- What are the imaging features of acute chest syndrome (ACS) complicating sickle cell disease on computed tomography (CT) and what is the diagnostic performance of bedside chest radiograph (CR)?

\section{What is the bottom line?}

- Lung consolidations were the most frequent infiltrates and predominated in lower lobes, whereas ground-glass opacities and atelectasis were less frequent and had a more homogenous distribution. Patients with segmental consolidations on CT scan had a more severe presentation and outcome as compared to those without. Bedside CR had a good sensitivity but a weak specificity for the radiological diagnosis of ACS.

\section{Why read on?}

- Upper lung-limited opacities might question the positive diagnosis of ACS. The bedside imaging diagnosis of ACS needs to be improved.

complete lung segment that is consistent with the presence of alveolar consolidation, but excluding atelectasis'. ${ }^{5}$ Identifying the characteristic lung imaging abnormalities of ACS may be challenging, especially when using bedside $\mathrm{CR}$, which has been shown to have moderate accuracy in other forms of acute lung injury. ${ }^{6}$ To be consistently useful, interpretation of a radiological investigation must be reliable. A reproducible radiological definition of ACS is crucial to ensure that study populations are homogeneous, especially in clinical trials that may consider ACS as an inclusion criterion or as a study outcome. Finally, the exact feature and distribution of lung lesions associated with ACS have not been described to date. CT scan, which is currently considered the reference imaging tool for lung structure exploration may help achieve this goal. The aim of the present study was threefold: (1) use CT scan to describe the main lung pathologic entities during ACS; (2) compare the characteristics and outcomes of patients with ACS according to the 
radiological definition used; for this purpose, we compared the most liberal definition ('a new pulmonary opacity'), ${ }^{13} 7$ to the most conservative one ('a new pulmonary opacity involving at least one complete lung segment, ie, consistent with the presence of alveolar consolidation, but excluding atelectasis') ${ }^{5}$; (3) assess the value of the bedside CR for the diagnosis of ACS, using CT scan as a reference.

\section{METHODS}

\section{Patients}

Consecutive adults ( $\geq 18$ years) with SCD admitted between July 2007 and December 2009 to Henri Mondor University Hospital (Créteil, France) with a diagnosis of ACS were prospectively included. The diagnosis of ACS by the attending physician was based on the association of a respiratory symptom (dyspnoea or chest pain), an abnormal lung sound at auscultation, and a new pulmonary opacity on the CR. ${ }^{8}$ The study was approved by our institutional ethics committee (Comité de Protection des Personnes Ile de France IX) as a component of standard care, and written and oral information was given to the patients. All patients received a uniform standardised treatment protocol of ACS, ${ }^{9}$ and low molecular weight heparin for thromboembolic disease prophylaxis. In patients diagnosed with ACS, a CT scan was ordered by the attending physician to search for pulmonary artery thrombosis, unless there was a contraindication to iodine agents, or the CT machine was unavailable. This study includes some patients previously described in a report focusing on pulmonary artery thrombosis during ACS. ${ }^{8}$

\section{CT scan and bedside CR}

All CT scan examinations were performed using a 64-row multidetector CT (Lightspeed VCT, General Electric, USA) with the following parameters: $600 \mathrm{mAs}, 120 \mathrm{kV}$, collimation of $0.625 \mathrm{~mm}$, reconstruction slice thickness of $0.625 \mathrm{~mm}$, pitch of 1 , and rotation time of $500 \mathrm{~ms}$. Axial scan was performed from the lung apices to the diaphragm. Typical scan time was $4 \mathrm{~s}$. Injection protocol consisted of the administration of $100 \mathrm{~mL}$ of non-ionic contrast medium (Iomeron 400, Bracco Imaging, France) injected at a rate of $3.5 \mathrm{~mL} / \mathrm{s}$ via a 18 -gauge peripheral intravenous catheter inserted in the antecubital vein or a central catheter, followed by a $40 \mathrm{~mL}$ saline flush, with bolus tracking. The approximate median CT volume dose index was $721 \mathrm{mGy}$. $\mathrm{cm}$. Anterior bedside CRs were obtained by using a Mobilett Plus apparatus (Siemens, France). All radiographs were obtained in supine or semirecumbent position, with standardised parameters (65 kV, 4-8 mAs according to body mass index) and focus-film distance $(1 \mathrm{~m})$.

\section{Image analysis}

Bedside CR images were first interpreted by attending physicians as part of their daily clinical work (a new pulmonary opacity was routinely required for ACS diagnosis). ${ }^{8}{ }^{10} \mathrm{CR}$ images underwent a subsequent review at the end of the study by two separate readers, both experts in the field of ACS (a senior radiologist and a senior pulmonologist), independently and without knowledge of the initial interpretation. They also blindly reviewed CT scan images by consensus at the end of the study. Two radiological definitions of ACS were used by reviewers: a liberal definition ('a new pulmonary opacity') ${ }^{1} 3^{7}$ and a conservative definition ('a new pulmonary opacity involving at least one complete lung segment, ie, consistent with the presence of alveolar consolidation, but excluding atelectasis'). ${ }^{5}$ Lung opacities on CR and CT scan were defined according to the Fleischner Society Glossary of Terms for Thoracic Imaging. ${ }^{11}$ Briefly, a consolidation was defined as a homogeneous increase in pulmonary parenchymal attenuation that obscured the margins of vessels and airway walls (an air bronchogram might be present). Atelectasis was defined by a reduced volume, accompanied by increased opacity (CR) or attenuation (CT scan) in the affected part of the lung. Ground-glass opacity was defined on CR as an area of hazy increased lung opacity, usually extensive, within which margins of pulmonary vessels may be indistinct; on CT scans, it was defined as hazy increased opacity of lung, with preservation of bronchial and vascular margins.

For each type of lung opacity on CT scan (consolidation, ground-glass and atelectasis), the reviewers rated the extent of involvement (subsegmental, segmental or lobar) in each lung lobe. The number of quadrants involved on bedside CR was also rated, based on the Lung Injury Score. ${ }^{12}$ All visible consolidations on CR were considered as involving at least one complete lung segment. Pulmonary artery thrombosis on CT scan was defined as a thrombus up to the segmental level, or multiple thrombi at the subsegmental level. ${ }^{8}{ }^{13}$ Analysis of right ventricle/left ventricle dimension ratios were performed in reconstructed four-chamber views, as previously described. ${ }^{14}$

\section{Statistical analysis}

Data were analysed using the SPSS Base 16.0 statistical software package (SPSS, Chicago, Illinois, USA). Normally distributed continuous data (according to the Kolmogorov-Smirnov test) were expressed as mean $\pm \mathrm{SD}$ and compared using the Student $\mathrm{t}$ test. Non-normally distributed continuous data were expressed as median (25th-75th percentiles) and compared using the Mann-Whitney test. Categorical variables, expressed as percentages, were evaluated using the $\chi^{2}$ test or Fisher's exact test. We tested the performance of reviewed bedside CRs for ACS diagnosis for each radiological definition (liberal and conservative), using CT scan as the reference. The agreement between blinded readers of bedside CRs was estimated for each radiological definition. ${ }^{15}$ We calculated raw agreement, chance-corrected agreement (kappa coefficient, to correct for high agreement by chance), ${ }^{16}$ and chance-independent agreement (phi coefficient, to take into account the proportion of positive ratings). ${ }^{17}$ Two-sided $\mathrm{p}$ values less than 0.05 were considered significant.

\section{RESULTS \\ ACS episodes}

The study flow chart is shown in figure 1. Among a total of 166 consecutive ACS episodes (in 127 patients), 21 were excluded because no CT scan was performed. The remaining 145 episodes explored with CT scan occurred in 118 patients, of whom 100 had a single ACS episode, 11 had 2 episodes, 5 had 3 episodes and 2 had 4 episodes; 102 patients had haematological and haemoglobin profiles indicating SS disease, 12 had SC disease, and 4 had haemoglobin S- $\beta$ thalassemia disease.

\section{Findings from CT scans}

CT scans were performed within $1(0-3)$ day of ACS onset without any complication. Among the 145 CT scans, four showed no opacity, and two exhibited isolated chronic opacities suggestive of interstitial pneumonia; 139 (96\%) CT scans were identified as positive for ACS according to the liberal definition (a new pulmonary opacity), whereas 84 (58\%) were identified as positive according to the conservative definition (a new complete lung segment consolidation) (figure 1). An illustrative example of positive CT scans according to the conservative definition is provided in figure 2. The anatomical distribution of lung opacities in patients with positive CT scans according to 
Figure 1 Study flow chart. ACS, acute chest syndrome. $C R$, chest radiograph.

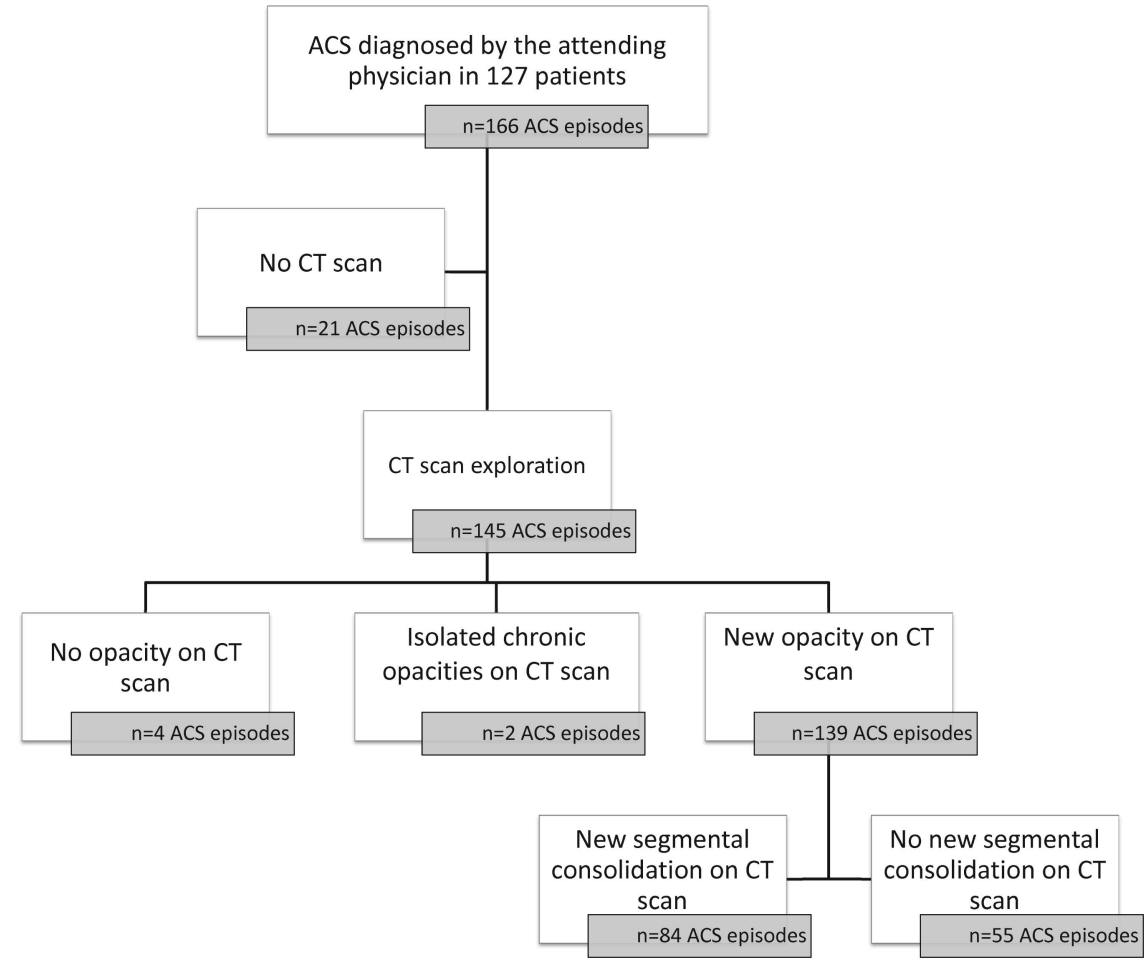

the two definitions is presented in figure 3A,B. Lung parenchyma was increasingly consolidated from apex to base; the right and left inferior lobes were involved frequently in patients with a new opacity on CT scan $(83 \%$ and $80 \%$ of cases, respectively, figure $3 \mathrm{~A}$ ), and almost always in patients with a new complete lung segment consolidation on CT scan $(98 \%$ and $95 \%$ of cases, respectively, figure 3B). Consolidations were predominant as compared with ground-glass opacities and atelectasis $(47 \%, 23 \%$ and $8 \%$ of lobes involved, respectively, in patients with a new opacity on CT scan, figure $3 \mathrm{~A}$; and $58 \%$, $26 \%$ and $6 \%$ of lobes involved, respectively, in patients with a new complete lung segment consolidation on CT scan, figure 3B). CT scans with a new opacity not involving at least one complete lung segment consolidation on CT scan showed subsegmental consolidations (in 29\% of lobes), ground-glass opacities (in 19\% of lobes) and atelectasis (in 10\% of lobes). Among patients with a new pulmonary opacity on CT scan, moderate to large pleural effusions were more frequent in those with at least one complete lung segment consolidation as compared with others, whereas the right ventricle/left ventricle ratio and pulmonary artery thrombosis prevalence were similar between groups (table 1).
Figure 2 Illustrative example of a patient with acute chest syndrome and bilateral consolidations predominating at lung bases on chest radiograph (panel A) and CT (panels B, C and D).
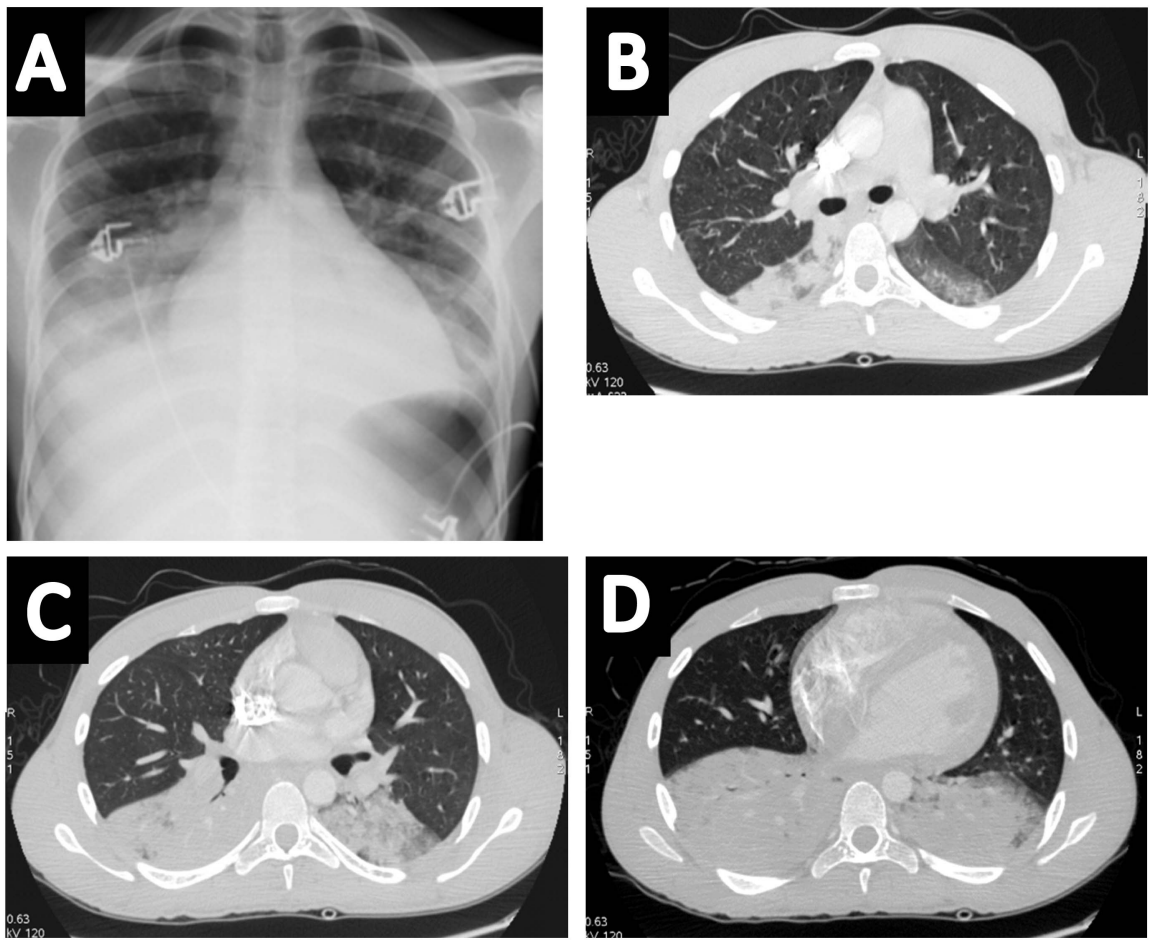
Figure 3 Distribution of lung opacities on $\mathrm{CT}$ according to lung segmentation during acute chest syndrome episodes with a new pulmonary opacity (panel $A, n=139$ ), or with a new pulmonary opacity including at least one new segmental consolidation (panel $B, n=84$ ). CUL, culmen; LIN, lingula; LL, lower lobe; $\mathrm{ML}$, middle lobe; UL, upper lobe.
A

Right lung

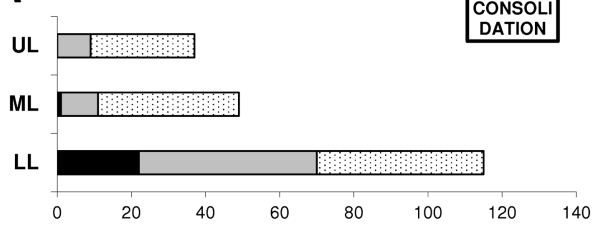

UL
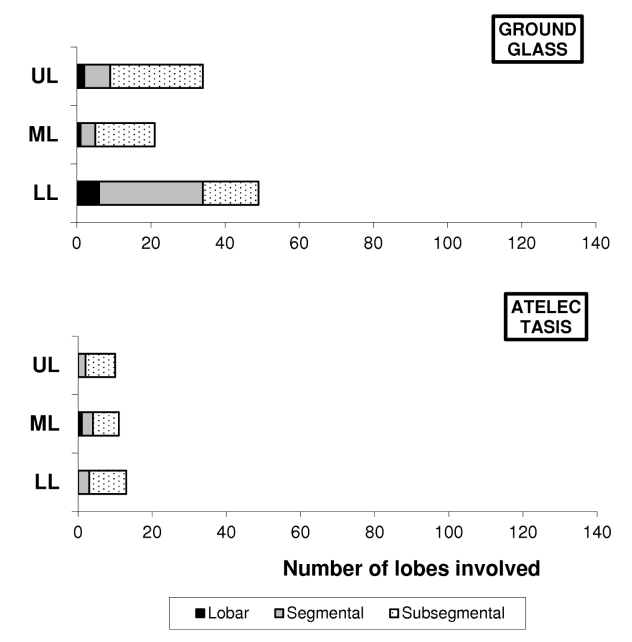

B

Right lung

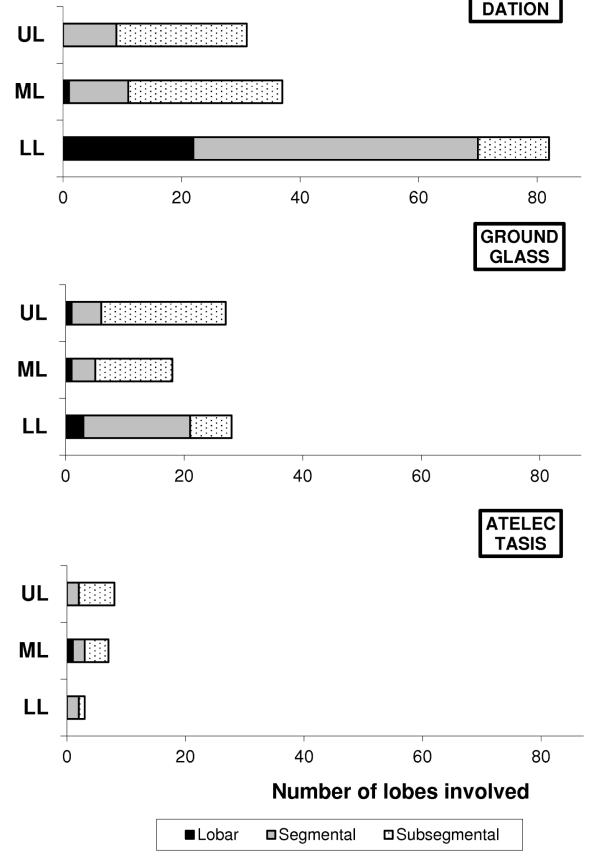

Left lung
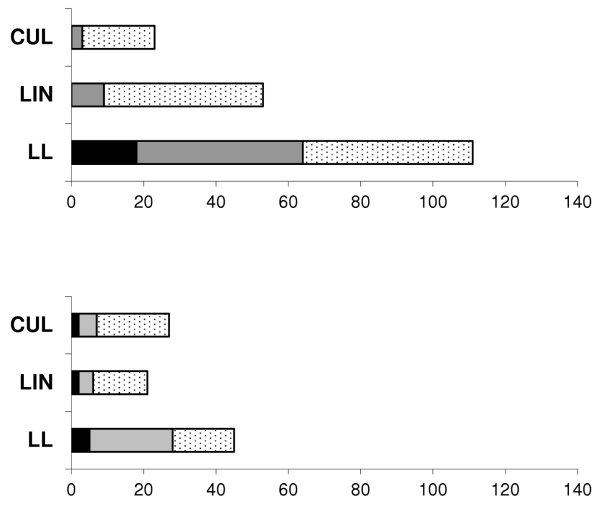

CUL 目

LIN 四

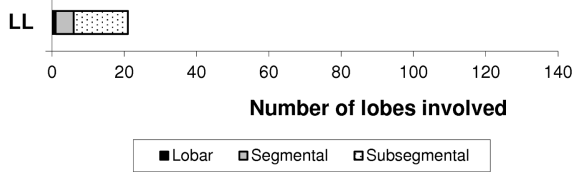

Left lung

CUL

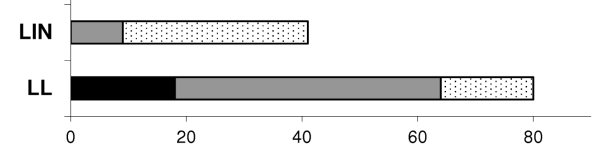

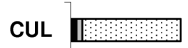

LIN
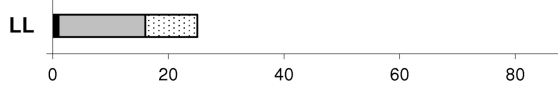

CUL

LIN 目

LL 口

\section{Association between $\mathrm{CT}$ scan findings and clinical and} laboratory data

Table 1 shows the clinical characteristics of patients with a new pulmonary opacity on CT scan at time of diagnosis of ACS. A precipitating factor for ACS was identified in 81 (58\%) cases, and was more frequent in patients with a new complete lung segment consolidation on CT scan as compared with others (table 1). Patients with a new complete lung segment consolidation on CT scan had less extrathoracic pain and higher respiratory rate during ACS; other physical findings were comparable between groups (table 1). At time of diagnosis of ACS and during hospital stay, white cell count and C-reactive protein concentration were higher in patients with a new complete lung segment consolidation on CT scan; other laboratory data, including haemolysis parameters were similar between groups (tables 1 and 2). The 139 ACS episodes with a new opacity on CT scan involved 116 patients, including 75 with at least one complete lung segment consolidation during at least one ACS episode and 41 without. Patients with a new complete lung segment consolidation on CT scan during at least one ACS episode were younger as compared with others; other baseline characteristics were similar between groups (table 3 ).

\section{Association between CT scan findings and outcome}

Treatments and outcomes of patients with a new pulmonary opacity on CT are reported in table 4 . There was more need for 
Table 1 Clinical and biological data at presentation of patients with acute chest syndrome and a new pulmonary opacity on CT

\begin{tabular}{|c|c|c|c|}
\hline \multirow[b]{2}{*}{ Parameter } & \multicolumn{2}{|c|}{$\begin{array}{l}\text { At least one complete lung } \\
\text { segment consolidation on CT }\end{array}$} & \multirow[b]{2}{*}{$\mathrm{p}$ Value } \\
\hline & No $(n=55)$ & Yes $(n=84)$ & \\
\hline Presence of a precipitating factor & $24(44 \%)$ & $57(68 \%)$ & $<0.01$ \\
\hline Type of precipitating factor & & & 0.02 \\
\hline Extrathoracic pain before ACS & $7(13 \%)$ & $30(15 \%)$ & \\
\hline Surgery & $2(4 \%)$ & $5(6 \%)$ & \\
\hline Infection & $2(4 \%)$ & $6(7 \%)$ & \\
\hline Other & $13(24 \%)$ & $16(19 \%)$ & \\
\hline \multicolumn{4}{|l|}{ Symptoms } \\
\hline Fever & $18(34 \%)$ & $37(45 \%)$ & 0.22 \\
\hline Chest pain & $51(96 \%)$ & $81(96 \%)$ & $>0.99$ \\
\hline Extrathoracic pain during ACS & $47(89 \%)$ & $60(71 \%)$ & 0.02 \\
\hline Haemoptysis & $0(0 \%)$ & $2(2 \%)$ & 0.52 \\
\hline Cough & $22(42 \%)$ & $34(41 \%)$ & 0.91 \\
\hline Pulmonary crackles & $39(74 \%)$ & $71(85 \%)$ & 0.12 \\
\hline Jugular venous distension & $2(4 \%)$ & $7(8 \%)$ & 0.48 \\
\hline \multicolumn{4}{|l|}{ Blood pressure, mmHg } \\
\hline Systolic & 120 [110-130] & 120 [114-130] & 0.07 \\
\hline Diastolic & $66[65-74]$ & $70[65-76]$ & 0.20 \\
\hline Heart rate, beats/minute & 100 [99-120] & 110 [100-120] & 0.12 \\
\hline Respiratory rate, breaths/minute & 26 [24-28] & $28[26-30]$ & $<0.01$ \\
\hline \multicolumn{4}{|l|}{ Blood gases } \\
\hline $\mathrm{PaO}_{2}, \mathrm{mmHg}$ & 74 [64-93] & 77 [65-96] & 0.49 \\
\hline $\mathrm{PaO}_{2} / \mathrm{FiO}_{2}$ ratio, $\mathrm{mmHg}$ & $305 \pm 75$ & $285 \pm 101$ & 0.22 \\
\hline $\mathrm{PaCO}_{2}, \mathrm{mmHg}$ & $43 \pm 7$ & $44 \pm 6$ & 0.21 \\
\hline $\mathrm{pH}$ & $7.41 \pm 0.05$ & $7.40 \pm 0.05$ & 0.29 \\
\hline $\mathrm{HCO}_{3}^{-}, \mathrm{mmol} / \mathrm{L}$ & $28 \pm 3$ & $28 \pm 3$ & 0.98 \\
\hline $\mathrm{SaO}_{2}, \%$ & 95 [90-97] & 94 [91-98] & 0.70 \\
\hline \multicolumn{4}{|l|}{ Laboratory values at ACS diagnosis } \\
\hline White cell count, $10^{9} / \mathrm{L}$ & $14.6 \pm 5.3$ & $18.0 \pm 6.0$ & $<0.01$ \\
\hline Platelet count, $10^{9} / \mathrm{L}$ & $353 \pm 143$ & $374 \pm 218$ & 0.54 \\
\hline \multicolumn{4}{|l|}{ Total haemoglobin, g/dL } \\
\hline All patients & $9.1 \pm 1.5$ & $8.7 \pm 1.6$ & 0.26 \\
\hline $\begin{array}{l}\text { SS patients only ( } n=123 \\
\text { episodes) }\end{array}$ & $9.0 \pm 1.5$ & $8.5 \pm 1.5$ & 0.07 \\
\hline Creatinine, $\mu \mathrm{mol} / \mathrm{L}$ & $65 \pm 21$ & $60 \pm 28$ & 0.24 \\
\hline C-reactive protein, $\mathrm{mg} / \mathrm{L}$ & $98 \pm 94$ & $141 \pm 94$ & 0.02 \\
\hline Alkaline phosphatase, IU/L & $91[73-126]$ & $101[76-136]$ & 0.41 \\
\hline Aspartate aminotransferase, IU/L & $48[31-66]$ & $40[29-68]$ & 0.40 \\
\hline Alanine aminotransferase, IU/L & 28 [20-59] & 29 [18-48] & 0.89 \\
\hline Total bilirubin, $\mu \mathrm{mol} / \mathrm{L}$ & $45[29-71]$ & 39 [26-64] & 0.57 \\
\hline Direct bilirubin, $\mu \mathrm{mol} / \mathrm{L}$ & $11[7-15]$ & 12 [8-19] & 0.27 \\
\hline Lactate dehydrogenase, IU/L & 552 [389-734] & $491[360-652]$ & 0.17 \\
\hline \multicolumn{4}{|l|}{ СТ } \\
\hline Pulmonary artery thrombosis & $9(16 \%)$ & $17(20 \%)$ & 0.57 \\
\hline $\begin{array}{l}\text { Right ventricle/left ventricle } \\
\text { ratio }\end{array}$ & $0.92[0.81-1.05]$ & $0.91[0.81-1.09]$ & 0.89 \\
\hline $\begin{array}{l}\text { Moderate to large pleural } \\
\text { effusion }\end{array}$ & $6(11 \%)$ & $27(32 \%)$ & $<0.01$ \\
\hline
\end{tabular}

antibiotic treatment and red blood cells transfusion in patients with a new complete lung segment consolidation on CT scan as compared with others. The maximal nasal oxygen flow was higher in patients with a new complete lung segment consolidation on CT scan, whereas the need for mechanical ventilation,
Table 2 Laboratory tests values recorded during the hospital stay of patients with acute chest syndrome and a new pulmonary opacity on CT

\begin{tabular}{|c|c|c|c|}
\hline \multirow[b]{2}{*}{ Parameter } & \multicolumn{2}{|c|}{$\begin{array}{l}\text { At least one complete lung } \\
\text { segment consolidation on } \mathrm{CT}\end{array}$} & \multirow[b]{2}{*}{$\mathrm{p}$ Value } \\
\hline & No $(n=55)$ & Yes $(n=84)$ & \\
\hline Highest leukocyte count, $10^{9} / \mathrm{L}$ & $15.6[11.9-19.3]$ & $17.8[15.1-24.6]$ & $<0.01$ \\
\hline Highest platelet count, $10^{9} / \mathrm{L}$ & 411 [313-529] & 457 [341-623] & 0.23 \\
\hline Lowest platelet count, $10^{9} / \mathrm{L}$ & 271 [203-334] & $240[171-344]$ & 0.19 \\
\hline Highest creatinine, $\mu \mathrm{mol} / \mathrm{L}$ & $67[57-80]$ & $62[53-78]$ & 0.20 \\
\hline Highest C-reactive protein, mg/L & $103 \pm 99$ & $143 \pm 95$ & 0.03 \\
\hline Highest alkaline phosphatase, IU/L & 98 [77-172] & 129 [87-189] & 0.10 \\
\hline $\begin{array}{l}\text { Highest aspartate } \\
\text { aminotransferase, IU/L }\end{array}$ & 52 [34-99] & $52[35-83]$ & 0.84 \\
\hline $\begin{array}{l}\text { Highest alanine aminotransferase, } \\
\text { IU/L }\end{array}$ & 38 [22-69] & 36 [24-58] & 0.94 \\
\hline Highest total bilirubin, $\mu \mathrm{mol} / \mathrm{L}$ & 54 [35-84] & $43[30-74]$ & 0.27 \\
\hline Highest direct bilirubin, $\mu \mathrm{mol} / \mathrm{L}$ & 14 [9-22] & 15 [10-25] & 0.47 \\
\hline $\begin{array}{l}\text { Highest lactate dehydrogenase, } \\
\text { IU/L }\end{array}$ & 623 [403-780] & 557 [378-820] & 0.60 \\
\hline
\end{tabular}

the hospital lengths of stay, and hospital deaths were similar between groups.

\section{Diagnostic capacity of CR}

Raw agreement between the two reviewers of bedside CR was substantial $(0.77$ for the liberal definition and 0.78 for the conservative definition), whereas, chance-corrected agreement was fair to moderate $(0.25$ for the liberal definition and 0.46 for the conservative definition) and chance-independent agreement was substantial $(0.63$ for the liberal definition and 0.68 for the conservative definition). The anatomical distribution of lung opacities in patients with positive $\mathrm{CR}$ according to the two definitions is presented in online supplementary figure S1A and S1B. Lower quadrants were more often involved as compared with upper quadrants. Among the $145 \mathrm{CT}$ scans performed, a bedside CR was available within $24 \mathrm{~h}$ of CT scan during 114 episodes. The value of the bedside CR for the diagnosis of ACS using $\mathrm{CT}$ as a reference could not be assessed for the liberal definition because all analysed $114 \mathrm{CT}$ scans were positive for that definition. Results for the conservative definition are shown in online supplementary table S1: the sensitivity of bedside CR was good for both readers ( $86 \%$ and $93 \%)$, whereas the specificity was weak $(51 \%$ and $56 \%)$. Illustrative examples of discrepancies between CT and CR are shown in figure 4. For both readers, the overall diagnostic accuracy of CR was comparable whether CT scans were performed on the day of ACS onset or later: 0.79 vs 0.71 and 0.79 vs 0.80 , respectively.

\section{Sensitivity analysis}

In order to test the robustness of our study, we verified the main findings while restricting the analysis to the first ACS episode. All main results were similar to those obtained while considering all ACS episodes (see online supplementary material).

\section{DISCUSSION}

Our study is the first to give a broad description of the main lung imaging pathologic entities during ACS using CT scan technology. Lung consolidations were the most frequent opacities and predominated in the bases; ground-glass opacities and 
Table 3 Baseline characteristics of patients presenting with acute chest syndrome and a new pulmonary opacity on CT

\begin{tabular}{|c|c|c|c|}
\hline \multirow[b]{2}{*}{ Parameter } & \multicolumn{2}{|c|}{$\begin{array}{l}\text { At least one complete lung } \\
\text { segment consolidation during } \\
\text { at least one ACS episode }\end{array}$} & \multirow[b]{2}{*}{$\mathrm{p}$ Value } \\
\hline & No $(n=41)$ & Yes $(n=75)$ & \\
\hline Age, years & $30[24-40]$ & 27 [23-32] & 0.04 \\
\hline Male gender & $18(44 \%)$ & $31(41 \%)$ & 0.79 \\
\hline Body mass index, $\mathrm{kg} / \mathrm{m}^{2}$ & $21 \pm 2$ & $21 \pm 2$ & 0.28 \\
\hline SS genotype & $35(85 \%)$ & $65(87 \%)$ & 0.85 \\
\hline Baseline total $\mathrm{Hb}, \mathrm{g} / \mathrm{dL}$ & $9.0[8.0-10.0]$ & $9.0[8.0-9.0]$ & 0.89 \\
\hline \multicolumn{4}{|l|}{ Past medical history: } \\
\hline Previous ACS & $34(85 \%)$ & $62(83 \%)$ & 0.75 \\
\hline $\begin{array}{l}\text { Number of previous ACS } \\
\text { episodes }\end{array}$ & $2[1-3]$ & $2[1-3]$ & 0.84 \\
\hline $\begin{array}{l}\text { Previous vaso-occlusive pain } \\
\text { crisis }\end{array}$ & $41(100 \%)$ & $19(100 \%)$ & $>0.99$ \\
\hline Stroke & $0(0 \%)$ & $2(3 \%)$ & 0.54 \\
\hline Retinopathy & $5(12 \%)$ & $8(11 \%)$ & 0.77 \\
\hline Priapism, \% males & $3(17 \%)$ & $7(23 \%)$ & $>0.99$ \\
\hline Bone necrosis & $10(24 \%)$ & $17(23 \%)$ & 0.83 \\
\hline Heart disease & $8(20 \%)$ & $5(7 \%)$ & 0.06 \\
\hline \multicolumn{4}{|l|}{ Treatments } \\
\hline Chronic transfusions & $5(13 \%)$ & $7(9 \%)$ & 0.75 \\
\hline Chronic hydroxyurea treatment & $18(45 \%)$ & $23(31 \%)$ & 0.13 \\
\hline $\begin{array}{l}\text { Long-term home oxygen therapy, } \\
\%\end{array}$ & $2(5 \%)$ & $3(4 \%)$ & $>0.99$ \\
\hline
\end{tabular}

atelectasis were less frequent and had a more homogenous distribution. Patients with a new complete lung segment consolidation on CT scan had a more severe presentation and outcome as compared to those without. Bedside CR had a good sensitivity but a weak specificity for the radiological diagnosis of ACS.

Lung consolidations were present in approximately one-half of lung lobes, ground-glass opacities in approximately one-quarter of lung lobes and atelectasis in $<10 \%$ of lung lobes. The predominance of lung consolidations during ACS as compared to other types of lung opacities is in accordance with previous studies. ${ }^{18}$ Consolidations are due to exudates or other products of disease that replace alveolar air, rendering the lung solid. ${ }^{11}$ Among suggested mechanisms responsible for the ACS, infection ${ }^{5}$ and infarction ${ }^{8}$ may typically induce lung consolidation. Groundglass opacities are caused by partial filling of airspaces, partial collapse of alveoli, interstitial thickening, increased capillary blood volume, or a combination of these. ${ }^{19}{ }^{20}$ Ground-glass opacity and consolidations may therefore belong to a common continuum in which alveolar air is displaced (ground-glass) or replaced (consolidation) by fluids or other products of disease. From this perspective, consolidations may correspond to a more severe disease as compared with ground-glass opacities. This hypothesis is in accordance with the finding that patients with at least one complete lung segment consolidation on CT scan had a more severe presentation and outcome as compared to those without a complete lung segment consolidation. Specifically, compared to patients with infiltrates without consolidation, the patients with at least one complete lung segment consolidated on CT scan had greater lung functional impairment (suggested by greater supplemental oxygen requirement), more severe
Table 4 Treatment and outcome of patients with acute chest syndrome and a new pulmonary opacity on CT

\begin{tabular}{|c|c|c|c|}
\hline \multirow[b]{2}{*}{ Parameter } & \multicolumn{2}{|c|}{$\begin{array}{l}\text { At least one complete lung } \\
\text { segment consolidation on } \\
\text { CT }\end{array}$} & \multirow{2}{*}{$\begin{array}{l}p \\
\text { Value }\end{array}$} \\
\hline & No $(n=55)$ & Yes $(n=84)$ & \\
\hline \multicolumn{4}{|l|}{ Treatment } \\
\hline Maximal nasal oxygen, L/min & $4[3-6]$ & $6[4-10]$ & $<0.01$ \\
\hline \multicolumn{4}{|l|}{ Mechanical ventilation } \\
\hline Non-invasive & $2(4 \%)$ & $5(6 \%)$ & 0.70 \\
\hline Invasive & $1(2 \%)$ & $3(4 \%)$ & $>0.99$ \\
\hline Antibiotic treatment & $26(48 \%)$ & $77(93 \%)$ & $<0.01$ \\
\hline Transfusions and phlebotomies & & & 0.06 \\
\hline Simple transfusion & $8(15 \%)$ & $9(11 \%)$ & \\
\hline Partial-exchange transfusion & $20(36 \%)$ & $49(58 \%)$ & \\
\hline Simple phlebotomy & $1(2 \%)$ & $0(0 \%)$ & \\
\hline $\begin{array}{l}\text { Total number of transfused red } \\
\text { blood cell units (in patients with } \\
\text { simple transfusion or } \\
\text { partial-exchange transfusion) }\end{array}$ & $1.0[0.0-2.0]$ & $2.0[0.0-4.0]$ & $<0.01$ \\
\hline $\begin{array}{l}\text { Total volume of exsanguinated } \\
\text { blood, mL (in patients with } \\
\text { partial-exchange transfusion or } \\
\text { phlebotomy) }\end{array}$ & $0[0-350]$ & $275[0-700]$ & 0.01 \\
\hline \multicolumn{4}{|l|}{ Outcome } \\
\hline Complicated ACS* & $28(51 \%)$ & $58(69 \%)$ & 0.03 \\
\hline Hospital stay, days & 8 [6-13] & 11 [7-13] & 0.09 \\
\hline Hospital deaths & $1(2 \%)$ & $0(0 \%)$ & 0.40 \\
\hline
\end{tabular}

inflammatory status (leukocyte count and C-reactive protein levels) at diagnosis and during the ACS episode, and a need for larger transfusions. These associations emphasise the ability of CT scan findings to accurately predict clinical severity, as well as the important role of inflammation in the pathophysiology of ACS. The use of a conservative radiological definition of ACS may therefore allow the selection of a relatively homogenous group of patients (while excluding the less severely ill) and this may be important when comparing studies and testing new therapeutic agents. Despite its rarity, atelectasis was present in some patients even when using the conservative definition. Atelectasis occurs because of reduced inflation of some part of the lung. ${ }^{11} 21$ The possible mechanisms during ACS may include respiratory inhibition because of pain and morphine treatment, passive collapse because of pleural effusion and supine position, resorption of air distal to airway obstruction being less likely.

The predominance of consolidations in lower lobes is in opposition to classical bacterial pneumonia (which usually shows no zonal predilection), ${ }^{22}$ but in accordance with findings in more diffuse forms of acute lung injury. Studies in patients with acute respiratory distress syndrome (ARDS) lying in the supine position found a basal predominance of consolidations ${ }^{23}$ that may be explained by increased lung weight caused by a high permeability-type oedema leading to a pressure gradient along the anteroposterior axis, ${ }^{24}$ a cephalic displacement of the diaphragm secondary to increased intra-abdominal pressure, ${ }^{23}$ or the pressure exerted by a dilated heart on subjacent lower lobes. ${ }^{25}{ }^{26}$ Several of these mechanisms may act during ACS. In particular, SCD patients may be prone to heart dilatation either due to chronic heart disease $^{27}$ or acute cor pulmonale during severe episodes of ACS. ${ }^{28}$ 

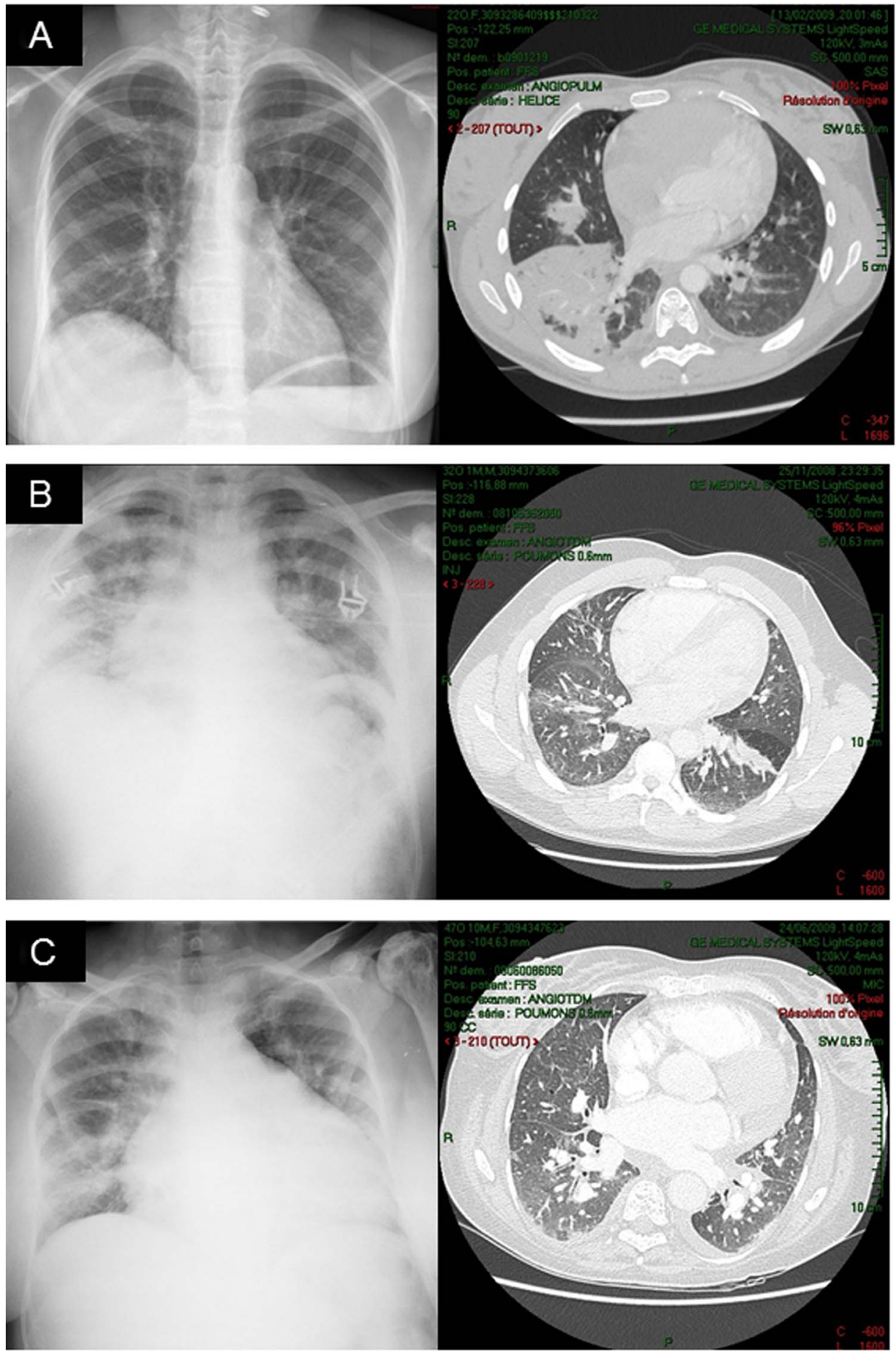

Figure 4 Illustrative examples of discrepancies between $C T$ and chest radiograph (CR) in patients with acute chest syndrome: Near-normal CR interpreted as showing minimal opacities with segmental consolidation on CT (panel A), CR interpreted as showing segmental consolidations with ground-glass opacities on CT (panels B and C).

These patients may also exhibit abdominal compartment syndrome in relation to immobilisation and morphine use for pain relief. Lung perfusion is anatomically mainly distributed towards the bases. Whether this distribution renders lung bases more prone to injury in the context of ACS where the increase in pulmonary vascular permeability may be typically haematologically driven needs further research.

In our study, chance-corrected agreement (kappa) between bedside CR readers was fair to moderate, whereas chance-independent agreement (phi) was substantial. This discrepancy may result from a limitation of the kappa coefficient, ${ }^{16}$ which is affected by the prevalence of the condition under consideration. ${ }^{29}$ Contrary to phi, kappa automatically decreases as the proportion of positive ratings becomes extreme (as for the liberal definition in our cohort), even if the way the raters interpret films does not change. ${ }^{29}$ The value of the bedside CR for the diagnosis of ACS (according to the conservative definition and using CT as a reference) was acceptable in terms of sensitivity but 
with a poor specificity. Previous reports highlighted that bedside CR was poorly correlated to lung CT images in patients with ARDS. ${ }^{30} 31$ Although bedside CR remains the main lung imaging modality in bedridden patients, technical limitations often reduce its quality, even with a careful procedure. ${ }^{32}$ These limitations include chest wall movements, patient rotation and supine position. Moreover, pleural effusion may be misdiagnosed as pulmonary consolidation or collapse on supine radiograph. Bedside lung ultrasonography has been shown as highly sensitive, specific and reproducible for diagnosing the main lung pathologic entities in patients with ARDS, with a higher diagnostic accuracy as compared to auscultation and bedside CR. ${ }^{31}$ Lung ultrasonography is also very accurate to discriminate pleural effusion and consolidation. Additionally, given the recurrence of ACS episodes during the lifespan of SCD patients, lung ultrasonography may allow reducing X-ray exposure. Further research is needed to test whether this imaging modality may prove useful in the bedside exploration of patients with ACS.

Our study has some limitations. First, we analysed a single CT scan during each ACS episode and could not assess its progression over time. Second, we included all ACS episodes during the study period as commonly performed in the ACS literature which is by nature a relapsing disease ${ }^{5} .{ }^{8}{ }^{28}$ Because all episodes may not be considered as being independent of one another, we confirmed our findings by a sensitivity analysis restricted to the first ACS episode.

In conclusion, ACS more frequently presented as a consolidation pattern followed by a ground-glass pattern on CT. Consolidation distribution was characterised by major gravity dependence. Upper lung-limited opacities might question the positive diagnosis of ACS. The diagnostic capacity of bedside $\mathrm{CR}$ is perfectible, and the bedside radiological diagnosis of ACS needs to be improved.

\author{
Author affiliations \\ ${ }^{1}$ Service de Réanimation Médicale, AP-HP, Groupe Henri-Mondor Albert-Chenevier, \\ Créteil, France \\ ${ }^{2}$ Faculté de Médecine, Université Paris Est Créteil, Créteil, France \\ ${ }^{3}$ INSERM, Unité U955, Créteil, France \\ ${ }^{4}$ Service d'Imagerie Médicale, AP-HP, Groupe Henri-Mondor Albert-Chenevier, \\ Créteil, France \\ ${ }^{5}$ AP-HP, Groupe Henri-Mondor Albert-Chenevier, Unité des Maladies du Globule \\ Rouge, Créteil, France \\ ${ }^{6}$ Service de Médecine Interne, AP-HP, Groupe Henri-Mondor Albert-Chenevier, \\ Créteil, France \\ ${ }^{7}$ Service de Physiologie-Explorations Fonctionnelles, AP-HP, Groupe Henri-Mondor \\ Albert-Chenevier, Créteil, France \\ ${ }^{8}$ Unité de Pneumologie, AP-HP, Groupe Henri-Mondor Albert-Chenevier, Créteil, \\ France
}

Acknowledgements All authors declared that they have no conflict of interest. We thank all radiologists and staff of the radiology unit of Henri Mondor University Hospital for their precious help.

Contributors AMD, JFD and BM designed research, undertook research, collected data, analysed data, wrote the paper and approved the final version. NA, AH, BG, $\mathrm{SA}, \mathrm{CBB}, \mathrm{FG}$ and $\mathrm{AR}$ undertook research, analysed data, wrote the paper and approved the final version.

Competing interests None.

Ethics approval Comité de Protection des Personnes lle de France IX.

Provenance and peer review Not commissioned; externally peer reviewed.

\section{REFERENCES}

1 Charache S, Scott JC, Charache P. "Acute chest syndrome" in adults with sickle cell anemia. Microbiology, treatment, and prevention. Arch Intern Med 1979;139:67-9.

2 Perronne V, Roberts-Harewood M, Bachir D, et al. Patterns of mortality in sickle cell disease in adults in France and England. Hematol J 2002;3:56-60.
3 Gill FM, Sleeper LA, Weiner SJ, et al. Clinical events in the first decade in a cohort of infants with sickle cell disease. Cooperative Study of Sickle Cell Disease. Blood 1995;86:776-83.

4 Vichinsky E, Williams R, Das $M$, et al. Pulmonary fat embolism: a distinct cause of severe acute chest syndrome in sickle cell anemia. Blood 1994;83:3107-12.

5 Vichinsky EP, Neumayr LD, Earles AN, et al. Causes and outcomes of the acute chest syndrome in sickle cell disease. National Acute Chest Syndrome Study Group. N Engl J Med 2000;342:1855-65.

6 Angoulvant $\mathrm{F}$, Llor J, Alberti $\mathrm{C}$, et al. Inter-observer variability in chest radiograph reading for diagnosing acute lung injury in children. Pediatr Pulmonol 2008;43:987-91

7 Maitre B, Habibi A, Roudot-Thoraval F, et al. Acute chest syndrome in adults with sickle cell disease. Chest 2000;117:1386-92.

8 Mekontso Dessap A, Deux JF, Abidi N, et al. Pulmonary artery thrombosis during acute chest syndrome in sickle cell disease. Am J Respir Crit Care Med 2011;184:1022-9.

9 Lionnet F, Arlet JB, Bartolucci P, et al. Guidelines for management of adult sickle cell disease.. Rev Med Interne 2009;30(Suppl 3):S162-223.

10 Vichinsky EP, Styles LA, Colangelo LH, et al. Acute chest syndrome in sickle cell disease: clinical presentation and course. Cooperative Study of Sickle Cell Disease. Blood 1997:89:1787-92

11 Hansell DM, Bankier AA, MacMahon $\mathrm{H}$, et al. Fleischner Society: glossary of terms for thoracic imaging. Radiology 2008;246:697-722.

12 Murray JF, Matthay MA, Luce JM, et al. An expanded definition of the adult respiratory distress syndrome. Am Rev Respir Dis 1988;138:720-3.

13 Torbicki A, Perrier A, Konstantinides S, et al. Guidelines on the diagnosis and management of acute pulmonary embolism: the Task Force for the Diagnosis and Management of Acute Pulmonary Embolism of the European Society of Cardiology (ESC). Eur Heart J 2008:29:2276-315.

14 Quiroz R, Kucher N, Schoepf UJ, et al. Right ventricular enlargement on chest computed tomography: prognostic role in acute pulmonary embolism. Circulation 2004;109:2401-4.

15 Meade MO, Cook RJ, Guyatt GH, et al. Interobserver variation in interpreting chest radiographs for the diagnosis of acute respiratory distress syndrome. Am J Respir Crit Care Med 2000;161:85-90.

16 Fleiss JL. Measuring nominal scale agreement among many raters. Psychological Bulletin 1971;76:378-82.

17 Cook RJ, Farewell VT. Conditional inference for subject-specific and marginal agreement: two families of agreement measures. Can J Statistics 1995; 23:333-44.

18 Bhalla M, Abboud MR, McLoud TC, et al. Acute chest syndrome in sickle cell disease: CT evidence of microvascular occlusion. Radiology 1993;187:45-9.

19 Remy-Jardin M, Remy J, Giraud F, et al. Computed tomography assessment of ground-glass opacity: semiology and significance. J Thorac Imaging 1993;8:249-64.

20 Hansell DM. Small-vessel diseases of the lung: CT-pathologic correlates. Radiology 2002;225:639-53.

21 Woodring JH, Reed JC. Types and mechanisms of pulmonary atelectasis. J ThoraC Imaging 1996;11:92-108.

22 Nambu A, Saito A, Araki T, et al. Chlamydia pneumoniae: comparison with findings of Mycoplasma pneumoniae and Streptococcus pneumoniae at thin-section CT. Radiology 2006;238:330-8.

23 Puybasset $\mathrm{L}$, Cluzel $\mathrm{P}$, Chao N, et al. A computed tomography scan assessment of regional lung volume in acute lung injury. The CT Scan ARDS Study Group. Am J Respir Crit Care Med 1998;158:1644-55.

24 Pelosi P, D'Andrea L, Vitale $G$, et al. Vertical gradient of regional lung inflation in adult respiratory distress syndrome. Am J Respir Crit Care Med 1994; 149:8-13.

25 Malbouisson LM, Busch CJ, Puybasset L, et al. Role of the heart in the loss of aeration characterizing lower lobes in acute respiratory distress syndrome. CT Scan ARDS Study Group. Am J Respir Crit Care Med 2000;161:2005-12.

26 Jardin F. Role of the heart in the loss of aeration characterizing lower lobes in acute respiratory distress syndrome. Am J Respir Crit Care Med 2001;164:171.

27 Ahmed S, Siddiqui AK, Sadiq A, et al. Echocardiographic abnormalities in sickle cell disease. Am J Hematol 2004;76:195-8.

28 Mekontso Dessap A, Leon R, Habibi A, et al. Pulmonary hypertension and cor pulmonale during severe acute chest syndrome in sickle cell disease. Am J Respir Crit Care Med 2008;177:646-53.

29 Maclure M, Willett WC. Misinterpretation and misuse of the kappa statistic. Am J Epidemiol 1987;126:161-9.

30 Rouby JJ, Puybasset L, Cluzel P, et al. Regional distribution of gas and tissue in acute respiratory distress syndrome. II. Physiological correlations and definition of an ARDS Severity Score. CT Scan ARDS Study Group. Intensive Care Med 2000;26:1046-56.

31 Lichtenstein D, Goldstein I, Mourgeon E, et al. Comparative diagnostic performances of auscultation, chest radiography, and lung ultrasonography in acute respiratory distress syndrome. Anesthesiology 2004;100:9-15.

32 Greenbaum DM, Marschall KE. The value of routine daily chest $x$-rays in intubated patients in the medical intensive care unit. Crit Care Med 1982;10:29-30. 